$$
\operatorname{CONF}-880512--9
$$

UCLA/PPG--1163

DE88 013612

\title{
EROSION AND REDEPOSITION BEHAVIOR OF SELECTED NET-CANDIDATE MATERIALS UNDER HIGH-FLUX HYDROGEN, DEUTERIUM PLASMA BOMBARDMENT IN PISCES
}

E. Franconi*, Y. Hirooka, R.W. Conn, W.K. Leung, B. LaBombard, and R.E. Nygren

UCLA-PPG-1163

June, 1988

Institute of Plasma and Fusion Reseanch

Department of Mechanical, Aerospace, and Nuclear Engineering

University of California, Los Angeles

Los Angeles, Califomia 90024

*On leave from Associazione Euratom-ENEA sulla Fusione,

CRE Frascati, CP 65, 00044, Frascati, Rome, Italy

Presented at the 8th PSI meeting at Jülich, FRG, May, 1988.

(Submitted to the Journal of Nuclear Materials.) 


\section{DECTADER}

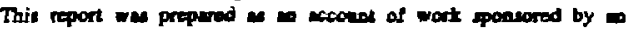
steacy of the Uniled Surtes Government. Neither the United Sinki Gowerment nor acy egency theroot, nor eny of theis

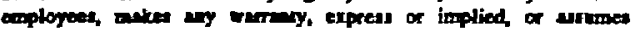
say legel liability or respontibility for the sccuracy,

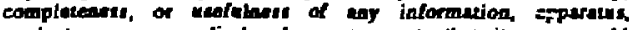
product, of prosest diecloned, or represenes tha its ole would aot ialrings peitwely orred rither. Refereace herein to any apecific compertids product, procens, of exrvice by trade theme. trademert, senufecturet, of otherwise, does oot necessurily constituts of izply its eadortement, recommenduzloa. or fevorits by the United Stutet Government of any etfery thereof. Tive views and opinions of enthors expersed hereio do dot necesturily stute or reflect thost of tho United Stulet Gowernmere of any aneney thereat. 
Erosion and Redeposition Behavior of Selocted NET-candidace Materials under High-Flux Hydrogen, Deulerium Plasma Bombardment in PISCES

\author{
E. Franconi*, Y. Firooka, R.W. Conn, \\ W.K. Leung, B. LaBombard, R.E. Nygren \\ Institute of Plasma and Fusion Research \\ and \\ Department of Mechanical, Aerospace, Nuclear Engineering \\ University of California, Los Angeles \\ Los Angeles, CA 90024, USA
}

\begin{abstract}
Plasma erosion and redeposition behavior of selected candidate materials for plasma-facing components in the NET-machine have been investigated using the PISCESA facility. Materials studied include SiC-impregnated graphite, 2D graphite weaves with. and without CVD-SiC coatings, and isotropic graphite. These specimens were exposed to continuous hydrogen or deuterium plasmas under the following conditions: electron temperature range from 5 to $35 \mathrm{eV}$; plasma density range from $5 \times 10^{11}$ to $1 \times 10^{12} \mathrm{~cm}^{-3}$; flux range from $5 \times 10^{17}$ to $2 \times 10^{18}$ ions $\mathrm{cm}^{-2} \mathrm{~s}^{-1}$; fluence of the order from $10^{21}$ to 1022

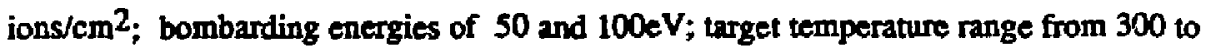
$1000{ }^{\circ} \mathrm{C}$. The erosion yield of SiC-impregnated graphite due to deuterium plasma bombandment is found to be a factor of 2 to 3 less than that of isotropic graphite materials. A further factor of 2-3 reduction in the erosion yield is observed in when redeposition associated with reionization of sputtered particle becomes significant. From postbombardment surface analysis with AES, the surface composition in terms of the Si/C of $\mathrm{SiC}$-impregnated graphite ratio is found to increase from 0.15 to 0.7 after hydrogen plasma bombardment to a fluence around $4 \times 10^{21}$ jons $/ \mathrm{cm}^{2}$ at $3500^{\circ}$. However, the final surface composition appears to remain unchanged up to $4 \times 10^{22} \mathrm{ions} / \mathrm{cm}^{2}$, the highest fluence in the present study. Significant surface morphological modifications of SiC-impregnated graphite are observed after the high-fluence plasma exposure. Several structural problems such as coating-substrate adhesion have been pointed out for SiC-coated 2D graphite weave.
\end{abstract}

* On leave from Associazione Euratom-ENEA sulla Fusione, CRE Frascati, CP 65, 00044 Frascati, Rome, Italy 


\section{INTRODUCTION}

The plasma-facing components in the NET (Next European Torus) machine are expected to tolerate a heat flux of $10-40 \mathrm{~W} / \mathrm{cm}^{2}$ and D-T plasma particle fluxes of the order of 1018 ions $\mathrm{cm}^{-2} \mathrm{~s}^{-1}$ for long pulses up to $1000 \mathrm{sec}$ [1]. Clearly, it is essential that candidate materials for these plasma-facing components be tested under similar high-flux and high-fluence hydrogen plasma bombardment. The PISCES-A facility [2] at UCLA allows us to investigate materials behavior under conditions relevant to those in NET.

With respect to materials selection, graphite is currently regarded as one of the most promising candidates because of its thermal properties and low atomic number. However, it is also true that graphite suffers from chemical erosion which leads to a formation of hydrocarbons [3]. This intrinsic weakmess of graphite might in part be compensated by modification of surface characteristics. One possible modification is to impregnate or coat a porous graphite material with $\mathrm{SiC}$, a material known to have a lower chemical erosion yield than graphite. In the present study, plasma bombardment experiments have been carried out for alteruative materials to graphite as candidates for plasma-facing components in NET.

\section{EXPERIMENTAL}

\subsection{Materials tested}

The materials tested here include: (1) SiC-impregnated graphite (Schunk-Ebe GmbH) with a nominal composition of $33 \% ; \mathrm{SiC}, 64 \% ; \mathrm{C}, 3 \% ; \mathrm{Si}$ (2) $2 \mathrm{D}$ graphite weave (Schunk-Ebe GmbH); (3) SiC coated 2D graphite weave (Schunk-Ebe GmbH); and (4) isotropic graphite (Le Carbonne Lorraine CL5890PT) which is currently lised for the limiter tiles in the JET tokamak.

\section{2-2. Plasma bombardment conditions}

A schematic diagram of the PISCES-A facility is shown in Fig. 1 . A disk specimen with a diameter of $2.5 \mathrm{~cm}$ was placed in continuous hydrogen or deuterium plasmas. A Langmuir probe was used to measure the plasma parameters. The plasma bombardment 
conditions are: plasma density range from $5 \times 10^{11}$ to $1 \times 10^{12} \mathrm{~cm}^{-3}$; electron temperature range from 5 to $30 \mathrm{eV}$; flux range from $5 \times 10^{17}$ to $2 \times 10^{18}$ ions $\mathrm{cm}^{-2} \mathrm{~s}^{-1}$; fluence range from $10^{20}$ to $10^{22}$ ions $/ \mathrm{cm}^{2}$; bombarding energy range from 50 to $100 \mathrm{eV}$. The specimen temperature was measured by a thermocouple and controlled in the range from 350 to $980^{\circ} \mathrm{C}$. These conditions are believed to be relevant to those expected in NET during normal operation. More details of the PISCES-A facility and materials experiments can be found elsewhere [2-5].

These experimental conditions span a range where sputtered particles freely escape the plasma (referred to as the erosion regime) to where electron impact ionization is important and significant redeposition of sputtered particles occurs (referred to as the redeposition regime). The important parameter to determine these two regimes is the mean free path for electron impact ionization of the sputtered material. Details will be described later.

\section{2-3. Post-hombardment analysis}

Plasma-bombarded specimens were weighed to determine the weight loss for evaluation of the erosion yield. Typical weight loss observed here was from a few tens to about hundred milli gram, which is easily differentiated from any air-exposure effects. Also, these specimens were analyzed with AES (Auger electron spectroscopy) to determine the surface composition and with SEM (scanning electron microscopy) to observe the surface morphology.

\section{RESULTS AND DISCUSSION}

\section{3-1. Basic considerations}

It is known from our previous studies [2-5] that the ionization mean free path of sputtered particles plays an important role in determining the overall materials erosion behavior under plasma bombardment in the PISCES-A facility. Generally, the ionization mean free path of sputtered particles, $\lambda$, can be calculated using the relation:

$$
\lambda=V_{\mathrm{av}} /\left(\mathrm{n}_{e}<\sigma v>\right),
$$


where $V_{2 v}$ is the averaged velocity over the energy distribution of the desorbing particles, $\mathrm{n}_{e}$ is the plasma density and $<\sigma v>$ is the rate coefficient for electron impact ionization. Here, the rate coefficient is evaluated from Lotz's formula [6]. Assuming a planer sufface potential, the energy distribution reeded to determine $V_{2 v}$ is given by the relation [7]:

$$
N(E)=E\left(E+E_{b}\right)^{3}
$$

where $E_{b}$ is the surface binding energy.

Resultant ionization mean free paths are listed in Table 1 for typical plasma parameters in the erosion and redeposition regimes. Because of the high surface binding energy, one should see a relatively long mean free path for physically sputtered carbon even under redeposition conditions. However, this effect will not significantly change the net erosion data to be discussed since chemical sputtering is considered to be the dominant erosion process at temperatures between 200 and $10000 \mathrm{C}$.

\section{3-2. Experimental valuation of selected NET-candidate materials}

The erosion yield of SiC-impregnated graphite and CL5890PT-graphite under deuterium plasma bombandment in the erosion regime at bombarding energies of 50 and $100 \mathrm{eV}$ are shown in Fig. 2 as a function of surface temperature in the range from 350 to $1000^{\circ} \mathrm{C}$. Corresponding data obtained from POCO-graphite (grade: HPD-1) from our previous work [9] are shown for comparison. The erosion yield data from CL5890PTgraphite and POCO-graphite are in relatively good agreement. One can also see that SiCimpregnated graphite exhibits a lower erosion yield than these isotropic graphite materials by a factor of 2 to 3 . Similar data have been reported earlier, using graphite materials doped with $\mathrm{SiC}$ to a relatively low concentration of $45 \%[9,10]$. The reduction of the erosion yield of SiC-doped graphite were interpreted by two possible mechanisms: (1) the virtual enrichment of silicon due to preferential removal of carbon from the surface; and/or (2) some catalytic effect of silicon as an enhanced hydrogen recombination site [10].

To clarify this point, SiC-impregnated graphite was bombarded with a hydrogen plasma up to a fluence of $4 \times 10^{22}$ ions $/ \mathrm{cm}^{2}$ at a surface temperature of $350^{\circ} \mathrm{C}$ in the erosion regime. After a certain period of hydrogen plasma bombardment, the surface composition was analyzed. To avoid surface impurity effects, the post-bombardment AES analysis was conducted under $2 \mathrm{keV} \mathrm{Ar}{ }^{+}$bombandment. 
The result of the surface analysis is shown in fig. 2 . One can see that the surface composition in terms of the Si/C ratio changes rapidly as a function of bombardment fluence up to $3-5 \times 10^{21}$ ions $/ \mathrm{cm}^{2}$ and then reaches an equilibrium value. Apparentiy, chemical erosion removes carbon first from the surface. An equilibrium composition is then attained up on a material balance of Si/C for given conditions: erosion rate; and segregation rate from the bulk. The equilibrium surface composition is expected to be maintained unless plasma bombardment conditions change. In fact, the equilibrium composition has been found to remain unchanged up to $4 \times 10^{22}$ ions $/ \mathrm{cm}^{2}$, the highest fluence in the present study. This fluence is equivalent to over 10,000 shots in existing tokamaks such as TFTR [11] and to about 100 shots in NET [1]. Also, the fluence above which the equilibrium surface composition was observed can be considered as the critical fluence, which is about 10 shots in NET, for the surface conditioning of this material.

The initial Si/C ratio of SiC-impregnated graphite before plasma bombardment is found to vary between 0.15 and 0.17 although the nomital ratio of this material is expected to be 0.25 from the vendor's data. This difference may be due to excess supply of carbon during the CVD-impregnation process. The equilibrium Si/C ratio after plasma exposure is found to be about 0.7 . Thus, significant enrichment of Si on the surface is observed here. For comparison, the data from a virgin specimen of SiC-impregnated graphite are also shown in Fig. 2. The virgin specimen (see curve: C+SiC-1) yielded about a factor of 2 larger erosion rate, relative to a spximen with an equilibrated surface composition (see curve: $\mathrm{C}+\mathrm{SiC}-2)$ at $350^{\circ} \mathrm{C}$ to a fluence of $4 \times 10^{21}$ ions $/ \mathrm{cm}^{2}$, a typical fluence used for individual crosion yield measurements. For successive experiments at higher temperatures, no significant difference is observed, indicating that the surface composition is equilibrated.

It should be noted here that although the composition dependenre on fiuence has been investigated at $350^{\circ} \mathrm{C}$, no corresponding data are available for higher temperatures at present. The equilibrium composition might depend on the surface temperature. However, it is also true that the erosion yield does not seem to depend strongly upon the concentration of SiC. In fact, we found a similar degree of reduction in the erosion yield using graphite impregnated with $33 \% \mathrm{SiC}$ to the earlier data using graphite doped with 4 $5 \% \mathrm{SiC}$. Therefore, we would rather deal with the present data, as measured, as an engineering benchmark.

The SiC-impregnated graphite specimen used for the high-fluence plasma bombardment experiment was analyzed with SEM and results are shown in Fig. 4. Due to physical and chemical sputtering, the surface morphology is significantly modified. However, no major cracks are observed, demonstrating good structural integrity. 
Nevertheless, there may be a limit in the practical use of SiC-impregnated graphite since this material is extremely hard, brittle and hence non-machinable by ordinary tools.

Similar high-fluence plasma erosion experiments attempted for SiC-coated 2D graphite weave were not successful because the coatings flaked off in part or entirely. It is essential that the film-substrate adhesion be improved before this material is reconsidered as a NET-candidate. Also, weight loss measurements for the plasma-bombarded 2D graphite weave specimens were found to be influenced significantly by air exposure, i.e. moisture pickup, probably because of the low density structure (about 70-75\% theoretical density). This is indicative of the possibility that one suffers significant outgassing if $2 \mathrm{D}$ graphite weave is placed in a vacuum system. For these reasons, the erosion yicld data from $2 \mathrm{D}$ graphite weaves with and without SiC-coatings were not reproducible and are not reported here.

Shown in Fig. 5 are the crosion yield data of SiC-impregaated graphite and CL5890PT-graphite at bombarding energies of 50 and $100 \mathrm{eV}$ at temperatures between 350 and $10000 \mathrm{C}$. One can see a significant energy dependerce for each material. At these bombarding energies, SiC-impregnated graphite exhibits a lower erosion yield than isotropic graphite. Also, the erosion yield of SiC-impregnated graphite steeply decreases towards $10000^{\circ}$. In our previous work [9], similar temperature dependence of the erosion yield was observed for POCO-graphite at an energy of $50 \mathrm{eV}$.

Reduposition experiments were carried out at a bombarding energy of $100 \mathrm{eV}$ at temperatures between 500 and $10000 \mathrm{C}$. Applying the probability of redeposition [4] for the mean free paths shown in Table 1 , one expects about 2-3\%, 50-60\% and 80-90\% redeposition for the cases of physically sputtered carbon, physically sputtered silicon and chemically sputtered deutero-methane $\left(\mathrm{CD}_{4}\right)$, respectively. The net erosion yield data obtained under these conditions are shown in Fig. 6. The net erosion yields SiCimpregnated graphite and CL5890PT-graphite in the redeposition regime are found to be about a factor of 2-3 lower than those in the erosion regime. In-situ plasma spectroscopic experiments for more detailed investigation of preferential erosion-redeposition behavior of multi-component materials are under way.

\section{SUMMARY AND AREAS TO BE INVESTIGATED IN FUTURE}

High-flux, high-fluence plasma erosion and redeposition experiments have been conducted, using the PISCES-A facility for selected NET-candidate materials: SiC- 
impregnated graphite; 2D graphite weaves with and withe-st SiC-coatings; and isotropic graphite. The following results are obtained:

(1) In the erosion regime, SiC-impregnated graphite has about a factor of 2-3 lower erosion yield than isotropic graphite at energies of 50 and $100 \mathrm{eV}$. A further faetor of 2 to 3 reduction in the net erosion yieid has been observed for each material in the redeposition regime.

(2) The surface composition of SiC-impregnated graphite in terms of the Si/C ratio first increases from $0.15-0.17$ to an equilibrium composition of 0.7 due to hydrogen plasma bombardment to a fluence of $3-5 \times 10^{21}$ ions $/ \mathrm{cm}^{2}$. The surface composition, once equilibrated, does not change as long as plasma bombardment conditions remain constant.

(3) After high-fluence hydrogen plasma bombardment, significant surface modifications are found for SiC-impregnated graphite. However, no major crack are observed, indicating good structural integrity of this material.

(4) During high-flux plasma exposure, SiC-coatings on 2D graphite weave tends to flake off. The improvement of substrate-coating adhesion is necessary. Also, bare $2 \mathrm{D}$ graphite weave absorbs an appreciable amount of water vapor. One might expect significant outgassing in a vacuum system after air-exposure.

The importance of the data reported here lies in the general reduction of the erosion yield from the use of SiC as an additive to the host graphite structure. However, details of the role of $\mathrm{SiC}$ in reducing the crosion yield are still unclear. One might raise a question, for example, what the best composition of $\mathrm{SiC}$ is to minimize the crosion yield. There might be an optimized composition to retain the gord machineability and thermomechanical properties of host graphite, and yet to minimize the erosion yield. To the besi of our knowledge, there is no comprehensive data base to answer this question at present. Clearly, in evaluating these SiC-graphite composites as possible candidates for NET, additional data on their responses to plasma exposure will be needed both to guide the development of materials and to project the performance of components in NET made from such materials.

\section{ACKNOWLEDGEMENT}

The authors would like to express their sincere gratitude to J.Bohdansky and D.M.Goebel for illuminating discussions. Special thanks go to K.Andrews, J.Eiverum and T.Sketchley for technical support. This work is supported by the Office of Fusion Energy, US Department of Energy under contract \#DE-AT03-84ER52104. 


\section{REFERENCES}

[1] F.Englemann, M.Chazalon, M.F.A.Harrison et.al., J.Nucl.Mater. 145-147 (1987) 154.

[2] D.M.Goebel, G.A.Campbeil and R.W.Conn, J.Nucl.Mater. 111\&112(1982)457.

[3] D.M.Goebel, Y.Hirooka, R.W.Cont et.aI., J.Nucl.Mater. 145-147(1987)61.

[4] Y.Hirooka, D.M.Goebel, R.W.Conn et.al., J.Nucl.Mater. 141-143(1986)193.

[5] Y.Hirooka, D.M.Goebel, R.W.Conn et.al., Nucl.Instr. \& Methods-B 23(1987)458.

[6] W.Lotz, Zeitschrift fur Physik 216(1968)241.

[7] M.W.Thompson, Philos. Mag. 18(1968)377.

[8] W.D.Langer, Nucl. Fusion 2: (1982)751.

[9] D.M.Goebel, J.Bohdansky, R.W.Conn ct.al., Nucl. Fusion (in press).

[10] J.Roth, J.Nucl.Mater. 145-147(1987)87.

[11] D.B.Heifetz, M.IBaskes, H.F.Dylla and M.Ulrickson, J.Nucl.Mater. $145-147(1987) 326$.

\section{FIGURE CAPTIONS}

Fig. 1: A schematic diagram of the PISCES-A facility.

Fig. 2: Erosion yields of SiC-impregnated graphite and isntropic graphite materials (CL5890PT and POCO: HPD-1[9]) under deuterium plasma bombardment at an energy of $100 \mathrm{eV}$ at temperatures between 350 and $1000^{\circ} \mathrm{C}$ in the erosion regime. The curves: $\mathrm{C}+\mathrm{SiC}-1 \mathrm{C}+\mathrm{SiC}-2$ are two series of erosion experiments starting with a virgin sursace and an equilibrated surface, respectively (see text).

Fig. 3: Surface composition change in terms of the $\mathrm{Si} / \mathrm{C}$ ratio of $\mathrm{SiC}$-impregnated graphite during high-fluence hydrogen plasma exposure at an energy of $100 \mathrm{eV}$ at a surface temperature of $350^{\circ} \mathrm{C}$ in the erosion regime. 
Fig. 4: Scanning electron micrographs of SiC-impregnated graphite: (a) as-received; and (b) after high-fluence plasma bombardment up to a fluence of $4 \times 10^{22}$ ions $/ \mathrm{cm}^{2}$ at $100 \mathrm{eV}$ and at $350 \mathrm{C}$.

Fig. 5: The crosion yields of SiC-impregnated graphite and isotropic graphite (CL5890PT) under deuterium plasmia bombardment at 50 and $100 \mathrm{eV}$ at temperatures between 350 and $1000^{\circ} \mathrm{C}$ in the erosion regime.

Fig. 6: Comparison of the erosion yields of SiC-impregnated graphite and isotropic graphite (CL5890PT) under deuterium plasma bombariment in the erosion and redeposition regimes at an energy of $100 \mathrm{eV}$ and at temperatures between 500 and $10000^{\circ}$. 
Table 1 Typical experimental parameters in the erosion and redeposition regimes.

PARAMEIERS

Plasma flux (ions s ${ }^{-1} \mathrm{~cm}^{-3}$ ) $\quad 1.0 \mathrm{e} 18$

7.0e11

5.0

350

45

$20-35\left(300-1000 C^{* * *}\right)$

Plasma dersity $\left(\mathrm{cm}^{-3}\right)$

Electron temperature $(\mathrm{eV})$

MFP* for carbon (cm)

MFP* for silicon (cm)

MFP* for methene (cm)
REDEPOSITION

$9.0 \mathrm{e} 11$

35.0

5.5

$1-3\left(300-1000^{\circ} C^{* *}\right)$

* The mem five puth for the first iomization by clectron impuct. the values are obtained from the Lotz's formula or datn reported by Langer [8].

** The mean free path is calsulated, assuming methane leaves with thermal energies given by the surface temeprature. 


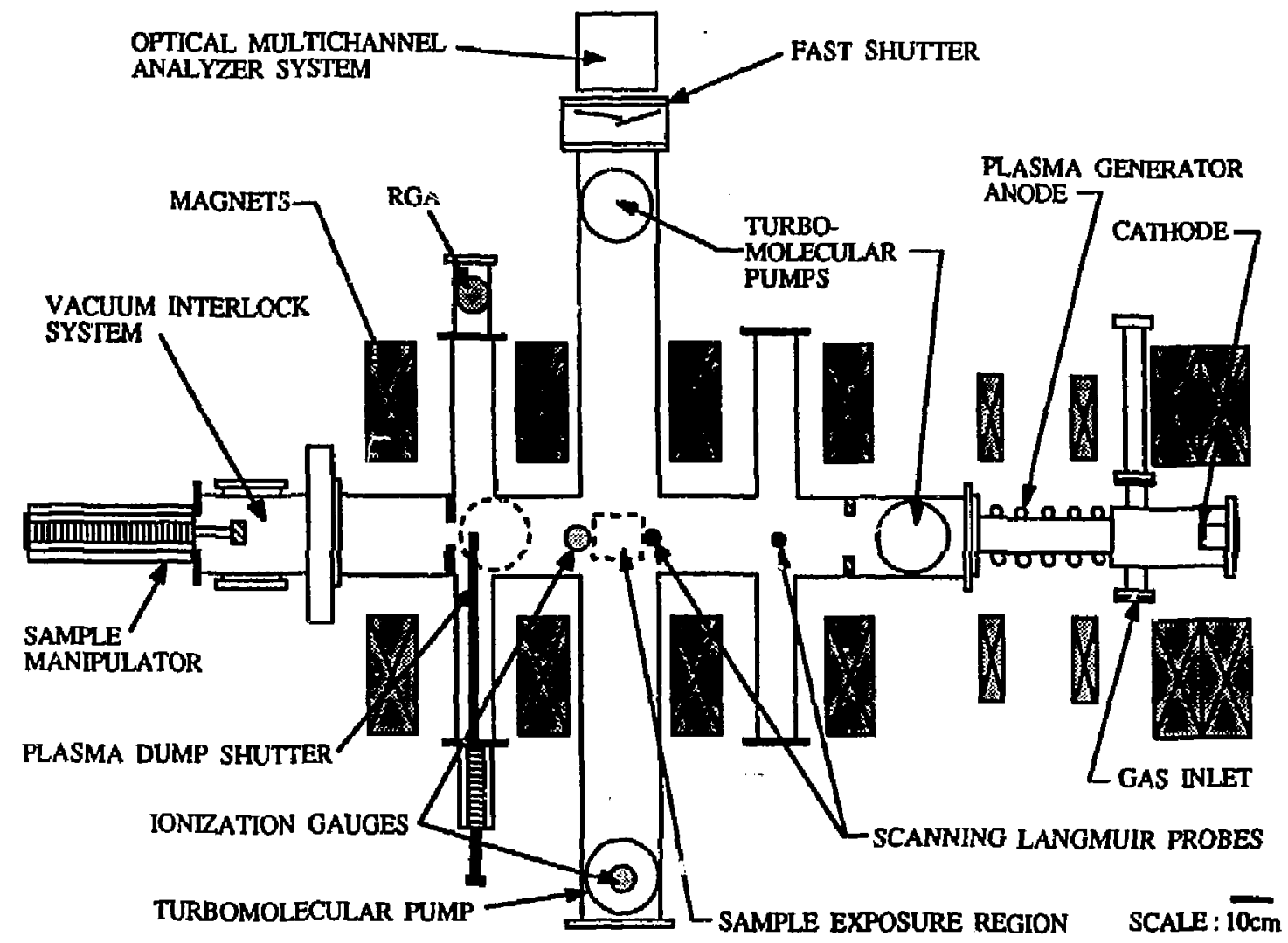

FIG. I 


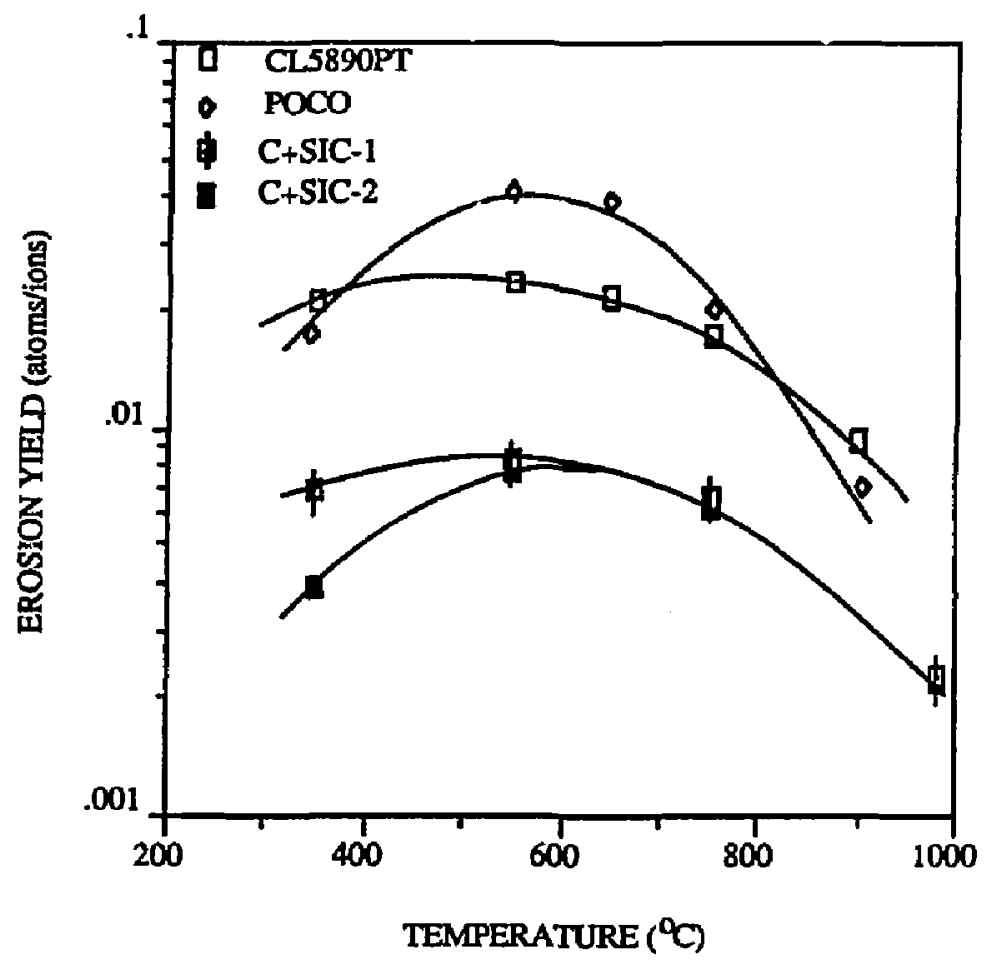

FIG. 2 


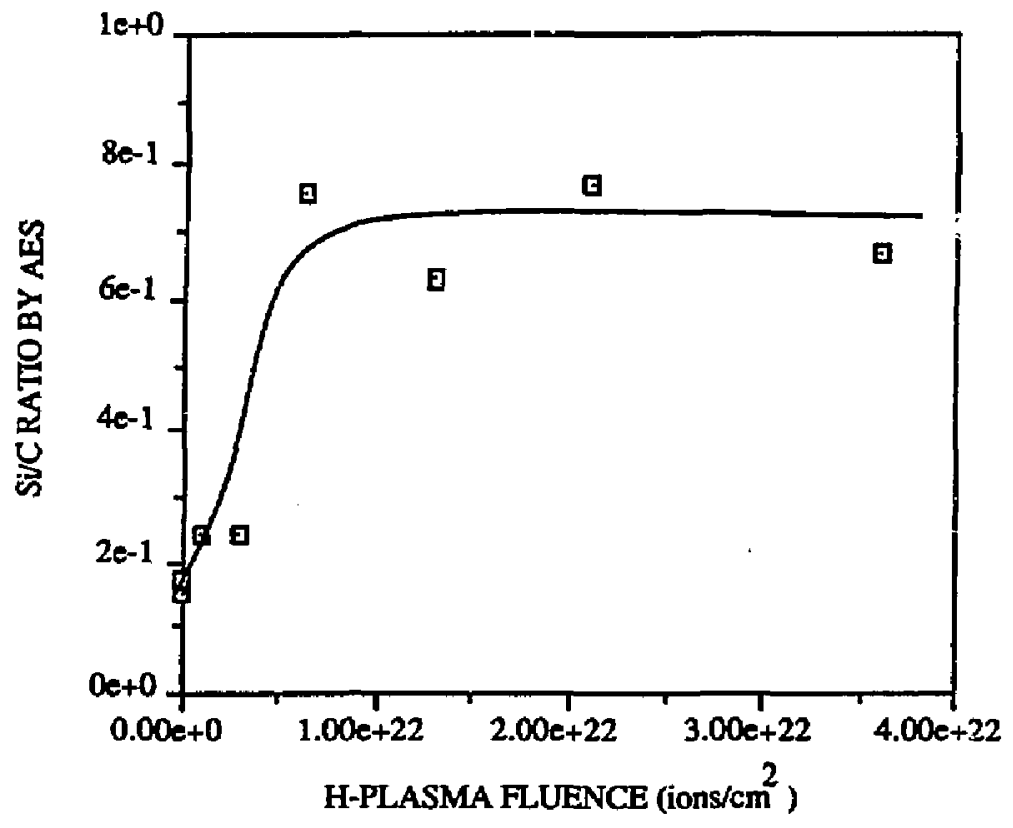

FIG. 3 

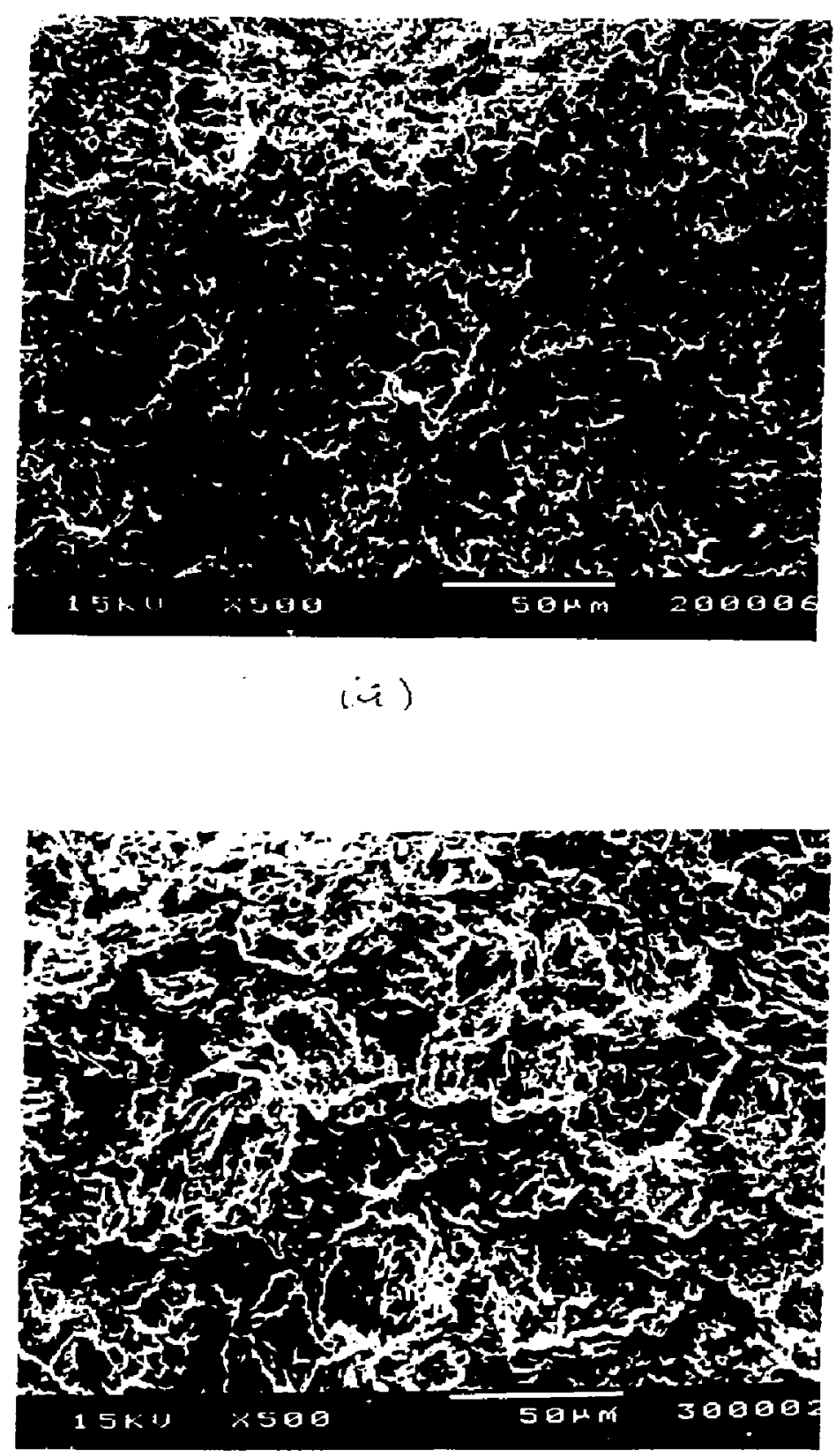


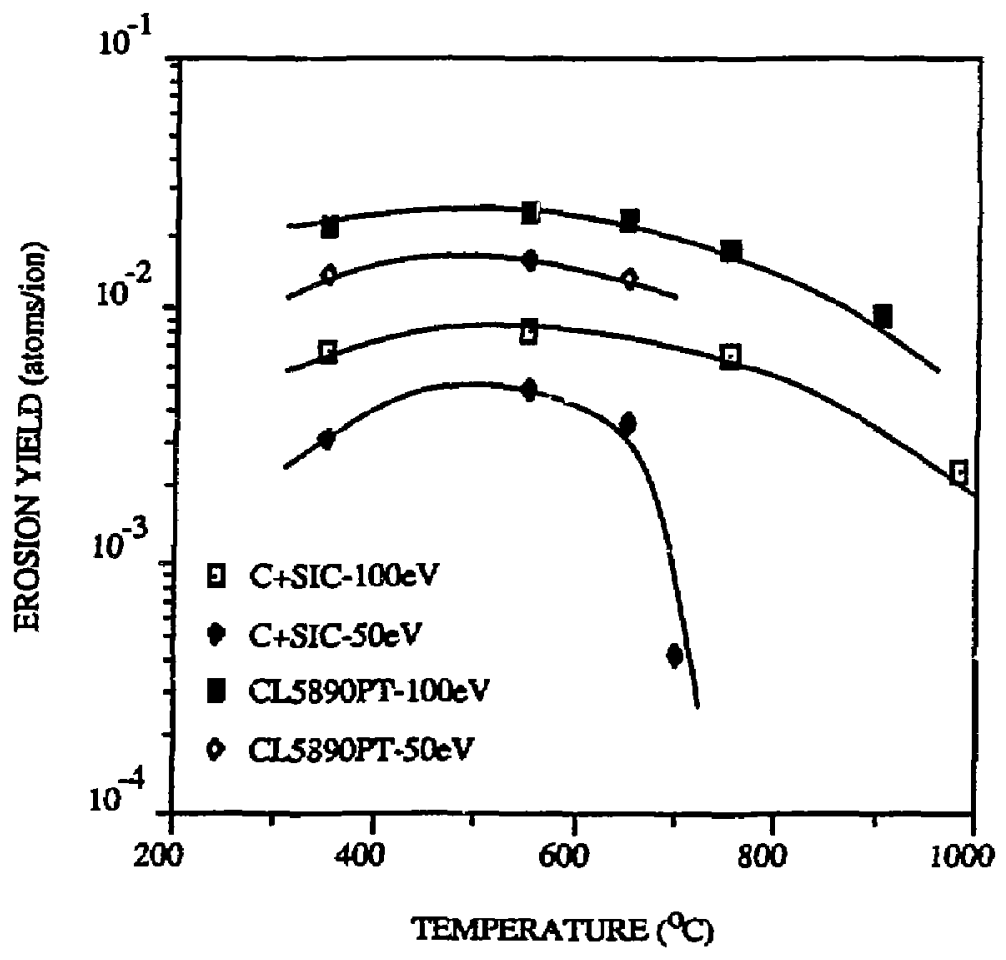

FIG.5 


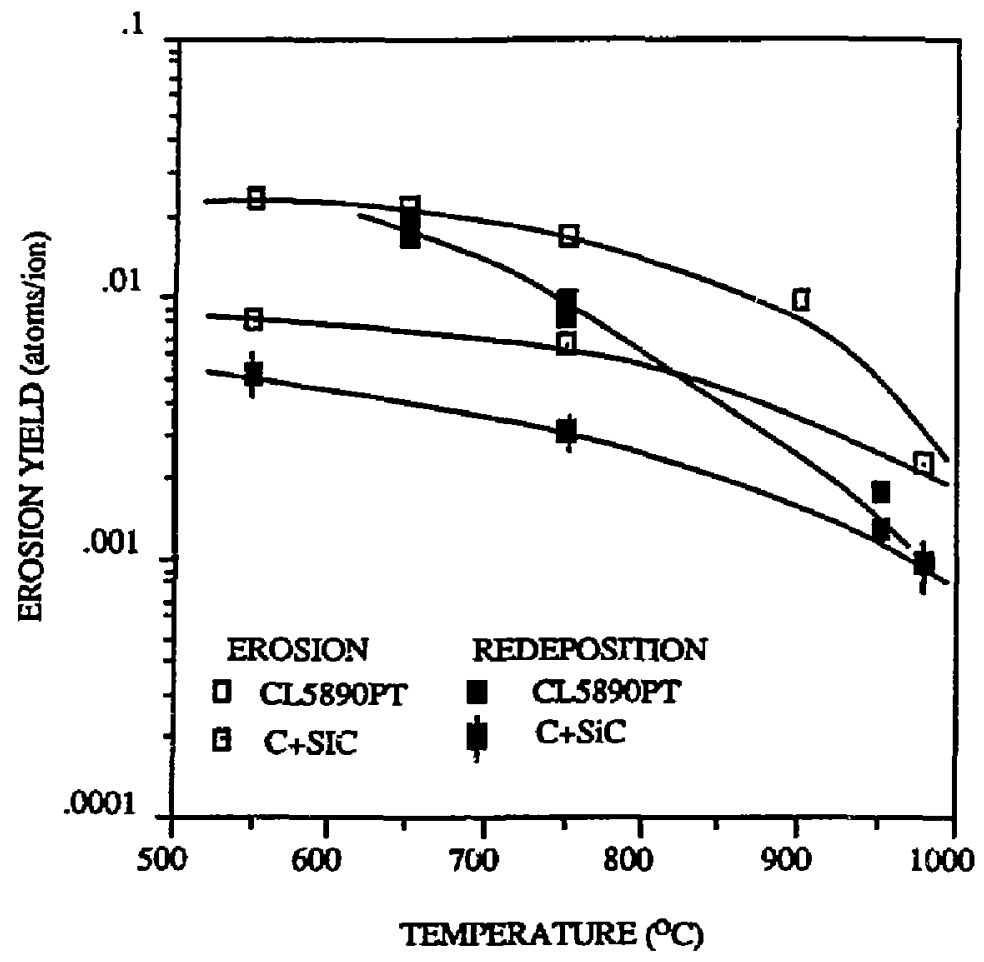

FIG., 6 